\title{
Multimodal imaging and treatment of bone metastasis
}

\author{
Eric L. Kaijzel · Thomas J. A. Snoeks • \\ Jeroen T. Buijs · Gabri van der Pluijm • \\ Clemens W. G. M. Löwik
}

Received: 24 April 2008/ Accepted: 29 September 2008/Published online: 22 October 2008

(C) The Author(s) 2008. This article is published with open access at Springerlink.com

\begin{abstract}
The role of molecular imaging in pre-clinical research is continuously evolving. Particularly in small animal models in biomedical research, optical imaging technologies are frequently used to visualize normal as well as aberrant cellular processes at a molecular-genetic or cellular level of function. Also in cancer metastasis research, whole body bioluminescent and fluorescent imaging techniques have become indispensable tools that allow non-invasive and real-time imaging of gene expression, tumor progression and metastasis, and response to therapeutic intervention. In this paper, we discuss the use of optical imaging strategies-either alone or in combination with CT- to study intrabone tumor growth, tumor progression and to monitor efficacy of therapeutic agents in metastatic bone disease.
\end{abstract}

Keywords Optical imaging - Bioluminescence .

Fluorescence - Bone metastasis - Bisphosphonates .

Bone morphogenetic protein-7 - Computed tomography

\section{Introduction}

Metastasis to bone and bone marrow occurs with high incidence in patients with advanced breast and prostate

E. L. Kaijzel $(\varangle)$ · T. J. A. Snoeks · J. T. Buijs ·

G. van der Pluijm - C. W. G. M. Löwik

Department of Endocrinology, Leiden University Medical

Center, C4-R, room 89, Albinusdreef 2, Leiden, ZA 2333,

The Netherlands

e-mail: E.L.Kaijzel@lumc.nl

J. T. Buijs · G. van der Pluijm

Department of Urology, Leiden University Medical Center, Leiden, The Netherlands cancer and frequently leads to skeletal complications like pathological fractures, bone pain, spinal cord and nerve compression, loss of motility and hypercalcemia of malignancy causing significant morbidity among these patients [1]. Bone metastases strongly affect bone remodeling involving the activation of bone degrading osteoclasts leading to osteolytic metastases (commonly observed in breast cancer) and activation of bone forming osteoblasts leading to osteosclerotic metastases that are typical of prostate cancers [2]. Because of the clinical significance of these processes, many research efforts are aimed at the understanding of the mechanisms by which tumor cells colonize the bone marrow and exploring novel possibilities to treat metastatic bone disease.

In order to study tumor progression and bone metastasis and to test novel therapeutic agents that can prevent or arrest excessive bone remodeling in vivo, the development of advanced imaging technologies in mouse models for cancer are critical for the assessment of these agents and to determine their potential value in clinical trials in patients affected with malignant bone metastasis.

\section{Small animal imaging in cancer}

The need for suitable model systems for the visualization of tumor progression and metastasis has led to the development of a variety of small animal imaging technologies like micro-computed tomography $(\mu \mathrm{CT})$ analysis, magnetic resonance imaging (MRI), nuclear medicine bone scans, skeletal scintigraphy and new imaging modalities based on the optical detection of reporter genes that are bioluminescent or fluorescent (reviewed in [3]). Imaging approaches like CT and MRI provide a high degree of spatial resolution and are better suited for tumor 
phenotyping and anatomical detail whereas PET and optical imaging are highly sensitive and therefore preferable for monitoring tumor cell burden, progression and metastasis (reviewed in [4]) that enable to detect early events of bone metastases.

In this review, we will focus on the use of (whole body) optical imaging modalities (Bioluminescent Imaging (BLI) and Fluorescent Imaging (FLI)) in combination with CT to study tumor development and metastasis to bone and possible therapeutic interventions of bone metastases.

\section{Whole body optical imaging}

\section{Whole body BLI}

Optical-based in vivo small animal imaging approaches detect photon emissions from within living tissues. Bioluminescence imaging has been developed over the last decade as a powerful tool for molecular imaging of small laboratory animals, enabling the study of ongoing biological processes in vivo [5]. A variety of different bioluminescent systems have been identified in nature, each requiring a specific enzyme and substrate. The most commonly used bioluminescent reporter for research purposes has been luciferase from the North American firefly (Photinus pyralis; FLuc) but other useful luciferases have also been cloned from jellyfish (Aequorea), sea pansy (Renilla; RLuc), corals (Tenilla), click beetle (Pyrophorus plagiophthalamus), and several bacterial species (Vibrio fischeri, V. harveyi) [6]. The FLuc protein is an excellent marker for kinetic and dynamic analyses of gene expression within short time frames because of its lack of post-transcriptional modications and its relatively short

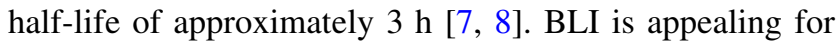
whole body imaging while mammalian tissues have low intrinsic bioluminescence and light is collected in the absence of external illumination sources causing almost no background activity resulting in an exceptionally high signal-to-noise ratio (SNR) making it very sensitive and specific. Also, the acquisition time of BLI measurements is short (seconds to a few minutes) compared to other imaging modalities and more animals can be analyzed at the same time.

\section{Whole body FLI}

Unlike BLI that is dependent on the addition of the substrate luciferin, FLI does not require a substrate addition but requires an external light source and depends in large part on the brightness of the fluorescent protein. Whole body FLI enables tracking of tumor growth and metastasis, gene expression, angiogenesis and bacterial infection, quantitatively (reviewed in [9]). Until recently, FLI suffered from several drawbacks due to the characteristics of the most commonly used fluorescent protein GFP. Due to its emission wavelength of around $520 \mathrm{~nm}$ significant autofluorescence and a relatively high signal absorption by the animal tissue is observed. These disadvantages have limited the sensitivity and specificity of GFP imaging. However, the use of selective filters and/or the application of spectral analysis have significantly reduced the contribution of autofluorescence to the acquired images [10]. When using fluorescent proteins with increasingly longer emission maxima (up to $649 \mathrm{~nm}$ ) like the series of redshifted proteins obtained by mutating dsRed, i.e., mFruits like mCherry, mTomato and mPlum [11, 12], and a series of recent developed very bright, red-shifted proteins derived from the anemone Entacmaea quadricolor like Katushka and mKate [13], the background autofluorescence can substantially be reduced and tissue penetration of light increased. Besides fluorescent proteins, common fluorophores, cyanines, quantum dots, peptide-based fluorescence probes, such as targeting, crosslinking and protease-activatable probes and 'inducible' gene reporters for bioluminescence have made it possible to non-invasively follow molecular processes involved in cancer development and treatment, including proteolysis [14, 15], bone turnover [16, 17], apoptosis [18, 19], and angiogenesis $[20,21]$.

\section{Comparison of whole body BLI and FLI}

In small animal optical imaging, fluorescent proteins/ probes and luciferases have both been employed to study transgene expression, tracking tumor growth/metastasis and treatment, and processes in disease (reviewed in [22]). Despite the similarities in their applications, each modality has its own characteristics with its strengths and weaknesses like differences in sensitivity, SNR and background emission form tissues. Quantitative comparisons of noninvasive BLI and FLI indicate that although fluorescent signals are generally brighter than bioluminescent signals, the latter show superior SNR especially in the green to red part in the spectrum resulting in a much higher sensitivity [23, 24]. However, fluorescence detection sensitivity and SNR improves at higher wavelengths where tissue autofluorescence is much lower and light propagation through tissue is higher [25]. Also, use of low-fluorescence diets reduces (intestinal) autofluorescence and enhances the potential of in vivo FLI [26]. The spatial resolution, which is depth- and optical-property-dependent, in 2D optical imaging is poor [27]. Current technology of tomographic fluorescence imaging, however, enables to measure signals with a spatial resolution of less than $1 \mathrm{~mm}$ [28]. Both FLI and BLI-based imaging techniques differ in the type of 
information obtained and can be applied differently in vivo for specific research questions. BLI is the most sensitive non-invasive method that enables the detection and tracking of a small number of metabolically active cancer cells in vivo in small animals [29] giving a better estimation of the actual tumor burden while FLI of fluorescent dyes are arguably more suitable for clinical applications in the near future. Advanced fluorescence imaging systems are able to sensitively detect NIR fluorophores with high resolution that should help to improve oncological surgical procedures [30, 31].

\section{Bone metastasis}

Monitoring tumor growth and bone/bone marrow metastases

Animal models of metastasis have been useful in the identification of metastasis-regulating genes as potential targets for therapy and have supported drug development [32-34]. Injection of tumor cells directly to the systemic circulation leads to the development of distant metastases throughout the animal body. However, the site of injection largely defines the site to which metastases develop since lateral tail-vein injection results primarily in pulmonary metastases whereas injection via the portal vein or spleen will result in liver metastases. Tumor cell injection into the left heart ventricle is a standard technique to induce bone metastasis. This way of inoculation introduces tumor cells to the arterial circulation leading to the colonization of cells to specific sites of the skeleton [35]. After intracardiac injection of luciferase-expressing human MDA-231-B breast cancer cells (MDA-231-B/luc ${ }^{+}$), very small amounts of photon-emitting tumor cells can be detected in bone marrow/bone within a few days, mimicking micro-metastatic spread. A more straightforward method to induce local growth in bone marrow is the intra-tibial injection of tumor cells [36, 37]. Estimation of the lowest cell number detectable in bone after direct inoculation of these cells into the marrow cavity of the femur revealed that as low as $2 \times 10^{4}$ cells could be detected with an total volume of the estimated lesion of $0.5 \mathrm{~mm}^{3}$ [36]. Quantification at different time points of the bioluminescent signal localized over the site of implantation enables continuous monitoring in vivo of tumor growth. This BLI-based metastasis model allows regular monitoring of the development and progression of experimental bone metastases in living animals with high sensitivity $[36,38]$.

Thus, monitoring of small metastatic deposits in bone marrow at a stage largely preceding tumor-induced osteolysis is feasible with BLI. This may help to better identify situations at risk for bone metastasis and develop novel therapeutic strategies that could be extended to the clinic.

Drug development and therapeutic intervention

Molecular imaging and bioluminescent imaging in particular, allows non-invasive, rapid and sensitive testing of (innovative) drugs and therapies for the treatment of cancer in animal models in relative high throughput compared to conventional drug testing [39-41]. The development of a fast growing number of BLI-based mouse models of disease enables the longitudinal monitoring of cytocidal effects of anti-neoplastic and antibiotic drugs in tumor burden [42], metastatic dissemination [43, 44], as well as viral [45] and bacterial infections [46]. BLI allows spatiotemporal and quantitative analysis of tumor growth and, due to its sensitivity, is ideally suited to evaluate the effectiveness of therapeutic approaches that target both early stages of metastatic development and advanced metastatic disease. It gives detailed information on localization and growth of minimal metastatic deposits in the bone marrow of experimental animals at stage largely preceding tumor detection by other methods. Apart from accelerating drug development, the use of optical imaging will also lead to a faster optimization of new therapies. Also, less laboratory animals are needed as due to the noninvasive nature of the methods repetitive measurements can be taken from the same animal, which also increases the reliability of observed effects. In bone metastatic studies, optical imaging can asses the effect of drugs in the early phase of the disease, especially the localization and growth of tumor cells within the bone and even before osteolysis occurs, whereas radiography (X-ray and CT) will only monitor bone destruction by detecting osteolytic lesions [44, 47].

Monitoring therapeutic efficacy in bone metastatic disease

Interference with the micro-environmental growth support system is currently being evaluated as a therapeutic strategy for the treatment of metastatic disease. Bone metastasis is a paradigm of the interactions that take place at the tumor-stroma interface [48, 49] and evidence from animal and clinical studies support the notion that bone turnover, particularly bone resorption, contributes substantially to initiation and maintenance of local tumor growth through the release of growth factors and bone-resorbing cytokines [50, 51]. Differently from other tissues, bone turnover can be reduced by pharmacologic means, e.g., by using bisphosphonates; thus, animal models of bone metastasis offer the unique opportunity to test in vivo the therapeutic efficacy of the interference with the tumor-stroma interface. 


\section{Bisphosphonates}

Bisphosphonates (BPs) are non-hydrolysable pyrophosphate analogs that have a high affinity for bone surfaces undergoing active resorption and exert a strong inhibitory effect on osteoclastic bone resorption. They exclusively accumulate in bone in vivo and are released in the bone microenvironment during osteoblastic bone resorption [52, 53].

Currently, BPs are the mainstay for long-term treatment of osteolytic bone disease and are used as bone-specific palliative treatments to reduce skeletal complications from bone-metastasizing tumors. They have been shown useful in treating prostate, breast, and lung cancer that metastasize to the skeleton [54-56]. We have recently reported on the action of BPs on development and growth progression of experimental bone metastasis [44]. BLI was used for the detection, monitoring and quantification of bone metastases induced by intracardiac or intraosseous injection of MDA$231-\mathrm{B} / \mathrm{luc}^{+}$in nude mice. The bisphosphonate olpadronate strongly inhibited tumor-induced osteolysis and its suppression of bone turnover, before bone colonization by intracardially injected cancer cells, significantly inhibited the number of developing bone metastases. Tumor growth in the few, but still developing bone metastases, was affected only transiently. Bone turnover reduction, however, had no effect on the growth and progression of established bone metastases as shown after intraosseous injection of cells (Fig. 1).

A later study on olpadronate in metastatic bone disease by Yang et al. [57] showed compelling results. After intraosseous injection of GFP-labeled human prostate cancer cells (PC-3-GFP) in nude mice, a dramatic reduction in the severity of bone lesions and an inhibition of the growth of the tumors by olpadronate treatment was found as measured with X-ray and whole-body fluorescence imaging, respectively.

These studies suggest that the anti-resorptive activity of bisphosphonates can reduce breast and prostate cancer metastasis to bone. This occurs most probably by reducing bone remodeling leading to a decrease of local factors that are normally released during the resorption process and that are involved in activation of micro-metastases. However, our data [44] also suggest that once micro-metastases
Fig. 1 Effects of

bisphosphonate treatment on intrabone growth of MDA-231$\mathrm{B} / \mathrm{luc}^{+}$breast cancer cells (BLI) and osteolysis (radiography) in tibiae of 6-week-old female nude mice. MDA-231-B/luc ${ }^{+}$ cells $(1 \times 105$ cells $)$ were inoculated directly into the right tibia of nude mice $(n=5)$ that were having a continuous release of high dose of olpadronate by osmotic minipumps $(16 \mu \mathrm{mol} / \mathrm{kg} / \mathrm{day}, 24 \mathrm{~h} /$ day for 28 days). a Effect on intrabone tumor growth was detected by BLI as described [36]. RLU = relative light units. b Effect on development of osteolytic lesions as assessed radiographically lytic area in $\mathrm{mm}^{2}$. c representative animals of the olpadronate treated and vehicle treated groups (BLI and radiography). Reproduced from [44]
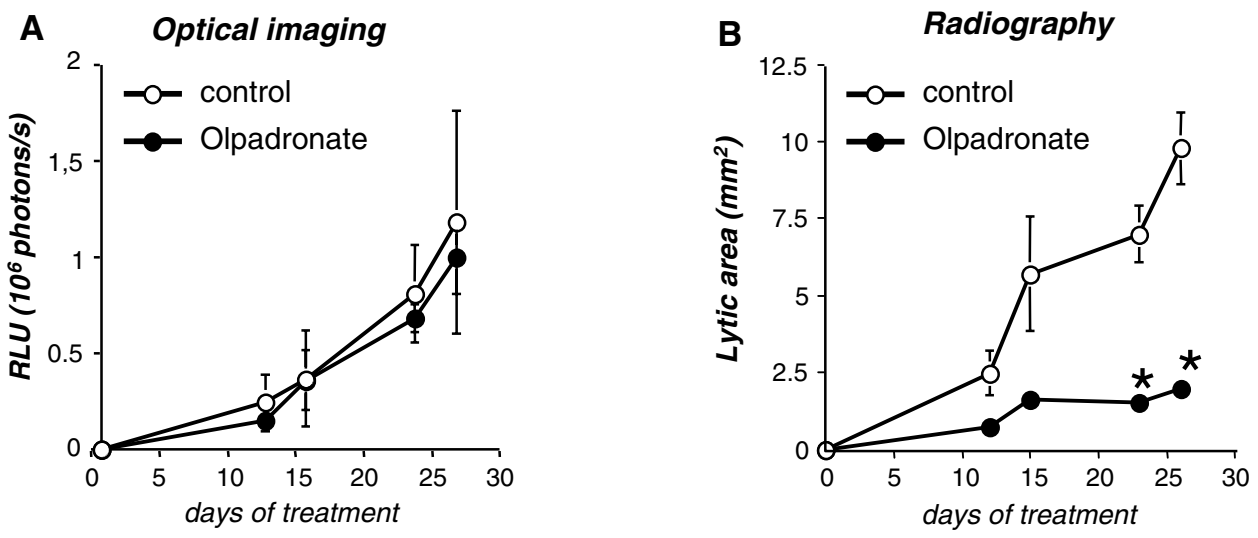

C

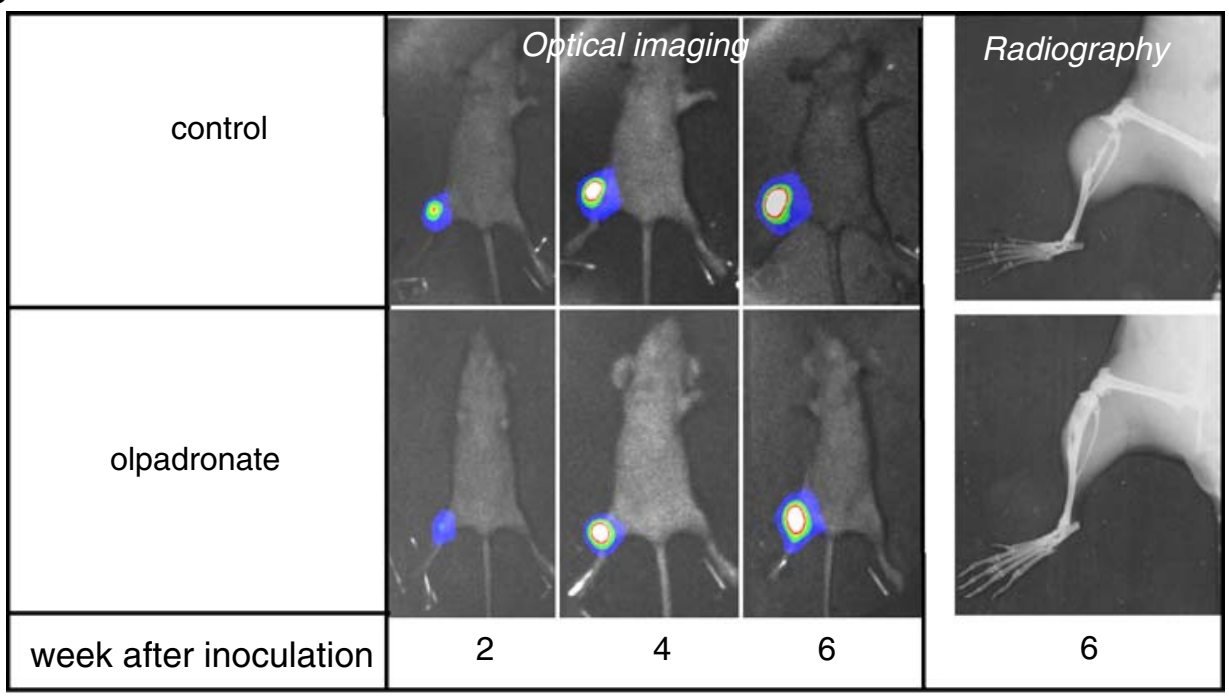


have turned into a macro-metastase or small tumor, it becomes independent of local bone turnover for its growth and, therefore, bisphosphonate treatment will not slowdown tumor progression of already established tumors in bone.

By labeling bisphosphonates, non-invasive molecular imaging of local changes in bone formation and resorption have become feasible in processes like bone metastasis. Radiolabeled bisphosphonates like alendronate, etidronate and methylene diphosphonate have become common imaging tools to identify places of high bone turnover in animal models and clinical practice [58-60]. Non-isotopic imaging of bisphosphonate analogs by covalently coupled pamidronate to a far-red fluorescent dye show the potential usefulness in the detection of bone remodeling activity, breast cancer micro-calcifications and local bone metabolism in vivo using far-red/NIR fluorescence imaging techniques [16, 17, 61]. However, compared to radiolabeled bisphosphonates, the detection of fluorescently labeled pamidronate is limited in deep structures as a result of soft-tissue attenuation and scatter [17].

\section{Transforming growth factor $\beta$ (TGF- $\beta$ ) and bone morphogenetic protein 7 (BMP7)}

The TGF- $\beta$ superfamily encompasses among others TGF $\beta$ and BMPs, which are involved in the regulation of embryonic development and tissue homeostasis [62]. In bone metastasis, TGF- $\beta$, among other cytokines, is released and activated by tumor-induced osteoclastic bone resorption. These tumor cells, stimulated by TGF- $\beta$, secrete more osteolytic factors (PTHrP, IL-6, IL-11) that can in turn further stimulate osteoclastic resorption and increase more TGF- $\beta$ release from bone. TGF- $\beta$ plays a central role in this feed-forward stimulation of osteoclastic bone resorption, referred to as the 'vicious cycle' of bone metastasis [43, 63-65]. It has long been recognized that TGF- $\beta$ can induce morphologic conversion, invasiveness, and migration in epithelial cells, collectively referred to as an epithelial-to-mesenchymal transition (EMT). EMT is not only critically important during the embryonic development, fibrosis and wound healing in adults, but also it appears to play a crucial role in tumor progression (reviewed in [66]). BMP7 as an antagonist of the TGF- $\beta$ pathway, however, was shown to induce the opposite process, the mesenchymal-to-epithelial transition (MET), in renal epithelial cells $[67,68]$.

Recently, we have demonstrated that BMP7 can counteract TGF- $\beta$ induced EMT in breast and prostate cancer cells in vitro and, more important, can inhibit formation of bone metastases. Daily systemic administration of BMP7 strongly and significantly impaired orthotopic and intrabone growth of human breast cancer cells (MDA-231-B/ $\mathrm{luc}^{+}$) in a BLI mouse model of bone metastasis most likely by counteracting the Smad-dependent TGF- $\beta$ signaling and EMT-process [47] (Fig. 2). This was in line with the data that overexpression of BMP7 in breast cancer cells inhibited tumorigenicity in vivo [47]. Moreover, BMP7 treatment also inhibited prostate cancer bone metastatic growth after intraosseous transplantation or intracardiac inoculation of human PC-3 M-Pro4/luc ${ }^{+}$[69]. However, in contrast to breast cancer, prostate cancer growth was not impaired after orthotopic implantation. Clearly, the tumor microenvironment is an important determinant of the therapeutic response to BMP7 in prostate cancer.

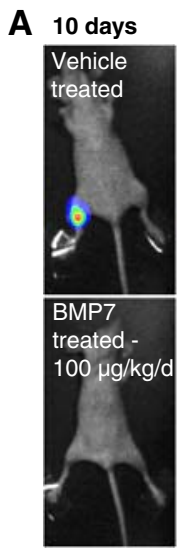

$B L I$

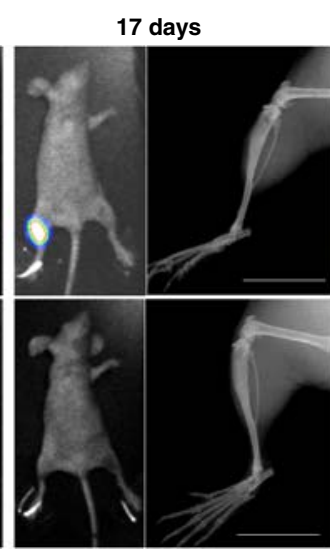

$B L I$
Radiography
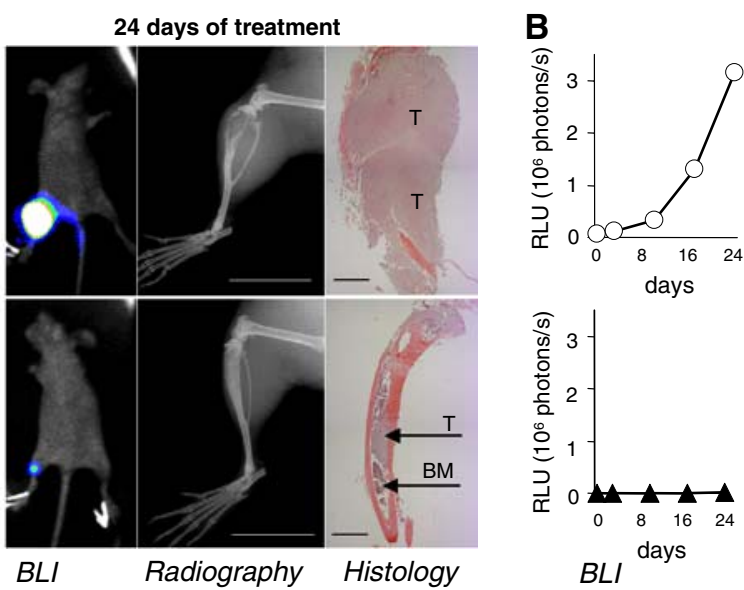

Fig. 2 Effect of BMP7 treatment on intrabone growth of MDA-231$\mathrm{B} / \mathrm{luc}^{+}$breast cancer cells (BLI) and osteolysis (radiography) in tibiae of 6-week-old female nude mice. MDA-231-B/luc ${ }^{+}$cells $(2.5 \times 105$ cells) were inoculated directly into the right tibia of nude mice $(n=5)$. Three days after inoculation, the animals were treated daily

with $100 \mu \mathrm{g} / \mathrm{kg}$ BMP7 or vehicle solution for 21 days. a Intrabone growth of tumor cells and tumor-induced osteolysis (BLI, radiography, and histology). $T$ tumor, $B M$ bone marrow. $\mathbf{b}$ Bioluminescence is quantified in RLU (105 photons/s). Reproduced from [47] 
Overall, BMP7 may represent a novel therapeutic molecule for repression of local and/or bone metastatic growth of osteotropic cancers like breast and prostate cancer.

\section{Combining optical imaging with CT and MRI}

One of the drawbacks of optical imaging is that so far, most equipment supported only the acquisition of two-dimensional planar images. In addition, where optical imaging provides superior sensitivity to detect genetic events (i.e., gene reporter activity), spatial resolution and anatomical detail is limited compared to structural imaging modalities such as micro-CT $(\mu \mathrm{CT})$. As a result, optical imaging only provides semi-quantitative data due to tissue-dependent signal attenuation and poor positional information due to photon scattering. However, new developments have made it possible to extend BLI and FLI to three-dimensional imaging by optical tomography providing better quantification of photon emission [70, 71]. Fluorescence molecular tomography can resolve and quantify fluorochromes deep in tissues through the use of tomographic principles. The resolution achieved in optical tomographic methods strongly depends on the depth and tissue dimensions and its optical properties. As yet, optical tomography provides a sensitive, but coarse 3D localization of the light source within the animal, as opposed to the $2 \mathrm{D}$ planar source localization in conventional optical systems. In complement, $\mu \mathrm{CT}$ and MRI systems provide superior resolution and anatomical detail. Three-dimensional FLI, BLI, $\mu$ CT and MRI individually have great value for performing studies in disease evaluation. We have demonstrated that in application related to metastatic bone disease, there is a clear benefit in combining 3D BLI with $\mu \mathrm{CT}$. By integrating tomographic BLI data sets with $\mu \mathrm{CT}$-images from the same animal, information about tumor location from the optical imaging with high resolution structural details on the skeleton for the $\mu \mathrm{CT}$ imaging could be acquired [72] (Fig. 3). This enables the direct study of the interaction between breast cancer metastasis and the skeletal system from the combined imaging which would not have been possible with any of the individual imaging modalities
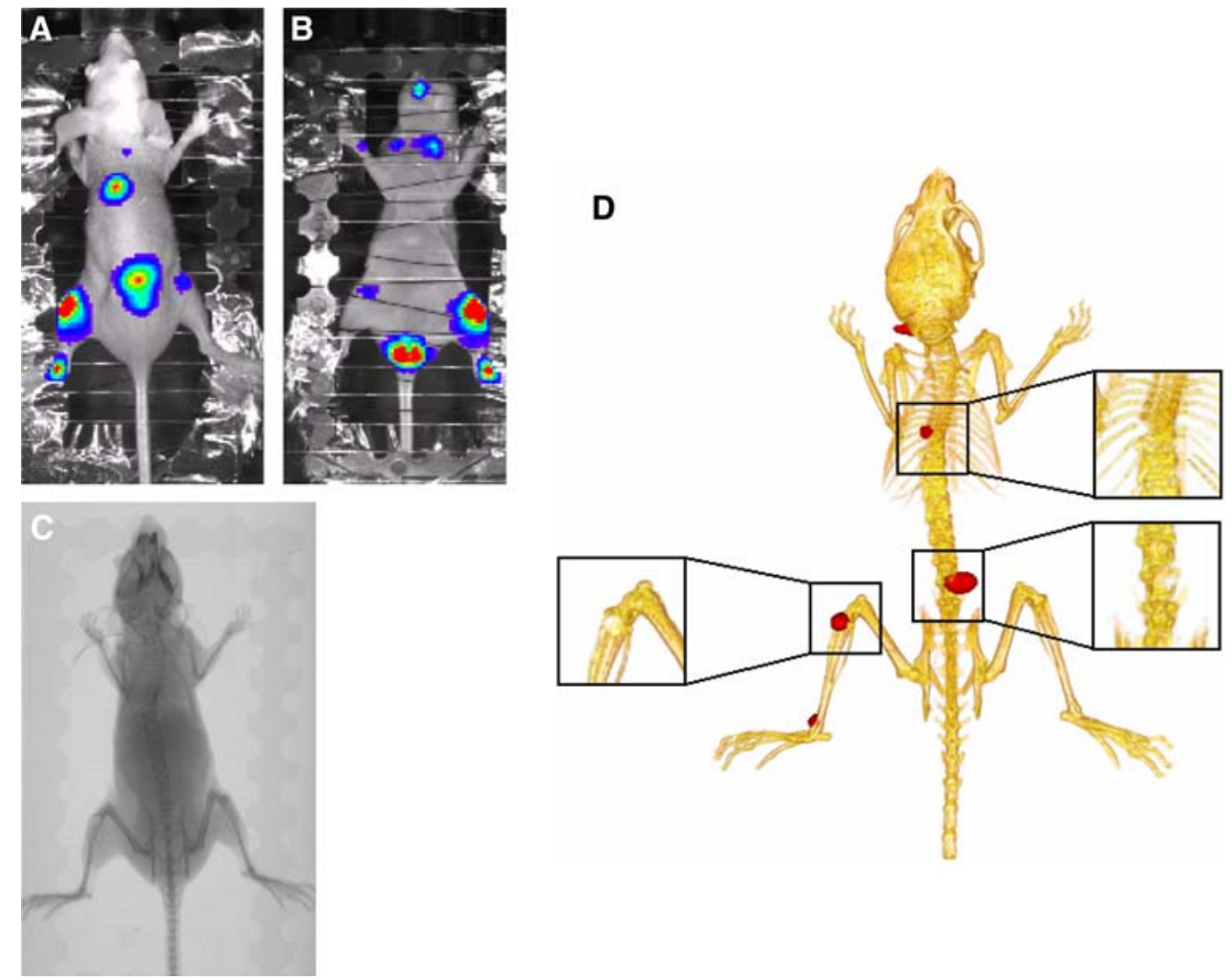

Fig. 3 Fused bioluminescence and micro-computed tomography visualization of a representative mouse intracardially injected with MDA-231-B/luc ${ }^{+}$breast cancer cells that developed extended bone metastases in spine, knee and ankle joints. Three to four weeks after intracardially inoculation of the MDA-231-B/luc ${ }^{+}$cells in nude mice $(n=3)$, bone metastases where analyzed with an IVIS 3D BLI Imaging system (Caliper LS, Hopkinton, MA, USA). Depicted are the BLI images of a representative mouse in supine (a) and prone position (b). The animal was subsequently scanned in a SkyScan $1178 \mu \mathrm{CT}$ scanner (SkyScan, Kontich, Belgium) (c). The cut-outs of the volume visualization of the fusion of the CT-images with the metastatic tumors to bone (d), clearly show bone destruction at the location of the metastatic breast cancer lesions in the computed tomography data, whereas the bioluminescence sources (red) highlight the potential lesion locations. Note that only the metastatic tumors to bone have been depicted in this fusion 
alone. Careful consideration should be made when determining the number of $\mu \mathrm{CT}$-scans while these scanners impose a relatively high ionizing radiation dose that may cause tissue damage in longitudinal studies [73]. Fusion of tomographic optical images with $\mu \mathrm{CT}$ or MRI will provide structural anatomic information with enhanced spatial resolution. Also, MR signals can localize sites of metastases prior to bone destruction of formation evident on $\mu \mathrm{CT}$. Furthermore, structural tissue information obtained by $\mu \mathrm{CT}$ and MRI, in combination with a mouse tissue atlas, can be used in an attempt to correct for tissue-dependent photon scattering and absorption. Multimodality imaging is a promising way to register and relate different imaging data into a singular context [74].

\section{Conclusions}

Effective treatments for bone metastases are not yet available and therefore, development of new therapeutics is required. It is clear from the work presented in this review and from work by others that optical imaging is well suited to detect and follow small numbers of cells non-invasively. It enables researchers to follow the fate of tumor cells during tumor progression and metastasis in a semi-quantitative manner. With the use of three-dimensional tomographic optical imaging systems and software based on a tissue atlas of the animal that attempts to correct for tissue absorption and scattering, more accurately quantitative data can be obtained. Optical imaging is not only a powerful tool in monitoring cancer development, progression and metastasis but also in functional studies of the pathogenesis of bone metastasis. It will allow us to identify novel in vivo molecular targets of cancer and detect their metastasis in small animals more accurately, thereby enhancing pre-clinical screening in small animals of new drugs and therapies.

Acknowledgments This work was supported in part by EC-FP6projects EMIL (LSHB-CT-2004-503569), DiMI (LSHB-CT-2005512146), PRIMA (FP6-504587) and PROMET (LSHC-CT-2006018858)

Open Access This article is distributed under the terms of the Creative Commons Attribution Noncommercial License which permits any noncommercial use, distribution, and reproduction in any medium, provided the original author(s) and source are credited.

\section{References}

1. Coleman RE (2001) Metastatic bone disease: clinical features, pathophysiology and treatment strategies. Cancer Treat Rev 27:165-176. doi:10.1053/ctrv.2000.0210

2. Roodman GD (2004) Mechanisms of bone metastasis. N Engl J Med 350:1655-1664. doi:10.1056/NEJMra030831
3. Massoud TF, Gambhir SS (2003) Molecular imaging in living subjects: seeing fundamental biological processes in a new light. Genes Dev 17:545-580. doi:10.1101/gad.1047403

4. Lyons SK (2005) Advances in imaging mouse tumour models in vivo. J Pathol 205:194-205. doi:10.1002/path.1697

5. Contag CH, Bachmann MH (2002) Advances in in vivo bioluminescence imaging of gene expression. Annu Rev Biomed Eng 4:235-260. doi:10.1146/annurev.bioeng.4.111901.093336

6. Hastings JW (1996) Chemistries and colors of bioluminescent reactions: a review. Gene 173:5-11. doi:10.1016/0378-1119(95) 00676-1

7. Thompson JF, Hayes LS, Lloyd DB (1991) Modulation of firefly luciferase stability and impact on studies of gene regulation. Gene 103:171-177. doi:10.1016/0378-1119(91)90270-L

8. Lipshutz GS, Gruber CA, Cao Y, Hardy J, Contag CH, Gaensler KM (2001) In utero delivery of adeno-associated viral vectors: intraperitoneal gene transfer produces long-term expression. Mol Ther 3:284-292. doi:10.1006/mthe.2001.0267

9. Hoffman RM (2005) The multiple uses of fluorescent proteins to visualize cancer in vivo. Nat Rev Cancer 5:796-806. doi: $10.1038 / \mathrm{nrc} 1717$

10. Mansfield JR, Gossage KW, Hoyt CC, Levenson RM (2005) Autofluorescence removal, multiplexing, and automated analysis methods for in-vivo fluorescence imaging. J Biomed Opt 10 : 41207. doi: $10.1117 / 1.2032458$

11. Shaner NC, Campbell RE, Steinbach PA, Giepmans BN, Palmer $\mathrm{AE}$, Tsien RY (2004) Improved monomeric red, orange and yellow fluorescent proteins derived from Discosoma sp. red fluorescent protein. Nat Biotechnol 22:1567-1572. doi:10.1038/ nbt1037

12. Wang L, Jackson WC, Steinbach PA, Tsien RY (2004) Evolution of new non-antibody proteins via iterative somatic hypermutation. Proc Natl Acad Sci USA 101:16745-16749. doi:10.1073/pnas. 0407752101

13. Shcherbo D, Merzlyak EM, Chepurnykh TV, Fradkov AF, Ermakova GV, Solovieva EA et al (2007) Bright far-red fluorescent protein for whole-body imaging. Nat Methods 4:741-746. doi: $10.1038 /$ nmeth 1083

14. Mahmood U, Weissleder R (2003) Near-infrared optical imaging of proteases in cancer. Mol Cancer Ther 2:489-496

15. Weissleder R, Tung CH, Mahmood U, Bogdanov AJ (1999) In vivo imaging of tumors with protease-activated near-infrared fluorescent probes. Nat Biotechnol 17:375-378. doi:10.1038/ 7933

16. Lenkinski RE, Ahmed M, Zaheer A, Frangioni JV, Goldberg SN (2003) Near-infrared fluorescence imaging of microcalcification in an animal model of breast cancer. Acad Radiol 10:1159-1164. doi:10.1016/S1076-6332(03)00253-8

17. Zaheer A, Lenkinski RE, Mahmood A, Jones AG, Cantley LC, Frangioni JV (2001) In vivo near-infrared fluorescence imaging of osteoblastic activity. Nat Biotechnol 19:1148-1154. doi:10.1038/nbt1201-1148

18. Laxman B, Hall DE, Bhojani MS, Hamstra DA, Chenevert TL, Ross BD et al (2002) Non-invasive real-time imaging of apoptosis. Proc Natl Acad Sci USA 99:16551-16555. doi:10.1073/ pnas.252644499

19. Schellenberger EA, Bogdanov A Jr, Petrovsky A, Ntziachristos V, Weissleder R, Josephson L (2003) Optical imaging of apoptosis as a biomarker of tumor response to chemotherapy. Neoplasia 5:187-192

20. Cai W, Shin DW, Chen K, Gheysens O, Cao Q, Wang SX et al (2006) Peptide-labeled near-infrared quantum dots for imaging tumor vasculature in living subjects. Nano Lett 6:669-676. doi: 10.1021/n1052405t

21. Chen X, Conti PS, Moats RA (2004) In vivo near-infrared fluorescence imaging of integrin alphavbeta3 in brain tumor 
xenografts. Cancer Res 64:8009-8014. doi:10.1158/0008-5472. CAN-04-1956

22. Weissleder R, Pittet MJ (2008) Imaging in the era of molecular oncology. Nature 452:580-589. doi:10.1038/nature06917

23. Choy G, O'Connor S, Diehn FE, Costouros N, Alexander HR, Choyke P et al (2003) Comparison of noninvasive fluorescent and bioluminescent small animal optical imaging. Biotechniques 35:1022-1030

24. Troy T, Jekic-McMullen D, Sambucetti L, Rice B (2004) Quantitative comparison of the sensitivity of detection of fluorescent and bioluminescent reporters in animal models. Mol Imaging 3:9-23. doi:10.1162/153535004773861688

25. Weissleder R, Ntziachristos V (2003) Shedding light onto live molecular targets. Nat Med 9:123-128. doi:10.1038/nm0103-123

26. Inoue Y, Izawa K, Kiryu S, Tojo A, Ohtomo K (2008) Diet and abdominal autofluorescence detected by in vivo fluorescence imaging of living mice. Mol Imaging 7:21-27

27. Rudin M, Weissleder R (2003) Molecular imaging in drug discovery and development. Nat Rev Drug Discov 2:123-131. doi: $10.1038 / \mathrm{nrd} 1007$

28. Zacharakis G, Ripoll J, Weissleder R, Ntziachristos V (2005) Fluorescent protein tomography scanner for small animal imaging. IEEE Trans Med Imaging 24:878-885. doi:10.1109/TMI. 2004.843254

29. Klerk CP, Overmeer RM, Niers TM, Versteeg HH, Richel DJ, Buckle T (2007) Validity of bioluminescence measurements for noninvasive in vivo imaging of tumor load in small animals. Biotechniques 43:7-13, 30

30. Kim S, Lim YT, Soltesz EG, De Grand AM, Lee J, Nakayama A et al (2004) Near-infrared fluorescent type II quantum dots for sentinel lymph node mapping. Nat Biotechnol 22:93-97. doi: $10.1038 /$ nbt920

31. Kirsch DG, Dinulescu DM, Miller JB, Grimm J, Santiago PM, Young NP et al (2007) A spatially and temporally restricted mouse model of soft tissue sarcoma. Nat Med 13:992-997. doi: $10.1038 / \mathrm{nm} 1602$

32. Steeg PS (2006) Tumor metastasis: mechanistic insights and clinical challenges. Nat Med 12:895-904. doi:10.1038/nm1469

33. Sharpless NE, Depinho RA (2006) The mighty mouse: genetically engineered mouse models in cancer drug development. Nat Rev Drug Discov 5:741-754. doi:10.1038/nrd2110

34. Eccles SA, Welch DR (2007) Metastasis: recent discoveries and novel treatment strategies. Lancet 369:1742-1757. doi:10.1016/ S0140-6736(07)60781-8

35. Arguello F, Baggs RB, Frantz CN (1988) A murine model of experimental metastasis to bone and bone marrow. Cancer Res 48:6876-6881

36. Wetterwald A, van der Pluijm G, Que I, Sijmons B, Buijs J, Karperien M (2002) Optical imaging of cancer metastasis to bone marrow: a mouse model of minimal residual disease. Am J Pathol 160:1143-1153

37. van der Pluijm G, Sijmons B, Vloedgraven H, Deckers M, Papapoulos S, Lowik C (2001) Monitoring metastatic behavior of human tumor cells in mice with species-specific polymerase chain reaction: elevated expression of angiogenesis and bone resorption stimulators by breast cancer in bone metastases. J Bone Miner Res 16:1077-1091. doi:10.1359/jbmr.2001.16. 6.1077

38. Kalikin LM, Schneider A, Thakur MA, Fridman Y, Griffin LB, Dunn RL et al (2003) In vivo visualization of metastatic prostate cancer and quantitation of disease progression in immunocompromised mice. Cancer Biol Ther 2:656-660

39. Rudin M, Rausch M, Stoeckli M (2005) Molecular imaging in drug discovery and development: potential and limitations of nonnuclear methods. Mol Imaging Biol 7:5-13. doi:10.1007/ s11307-004-0954-z
40. El Deiry WS, Sigman CC, Kelloff GJ (2006) Imaging and oncologic drug development. J Clin Oncol 24:3261-3273. doi: 10.1200/JCO.2006.06.5623

41. Gross S, Piwnica-Worms D (2006) Molecular imaging strategies for drug discovery and development. Curr Opin Chem Biol 10:334-342. doi:10.1016/j.cbpa.2006.06.028

42. Shachaf CM, Kopelman AM, Arvanitis C, Karlsson A, Beer S, Mandl S et al (2004) MYC inactivation uncovers pluripotent differentiation and tumour dormancy in hepatocellular cancer. Nature 431:1112-1117. doi:10.1038/nature03043

43. Deckers M, van Dinther M, Buijs J, Que I, Lowik C, van der Pluijm $\mathrm{G}$ et al (2006) The tumor suppressor Smad4 is required for transforming growth factor beta-induced epithelial to mesenchymal transition and bone metastasis of breast cancer cells. Cancer Res 66:2202-2209. doi:10.1158/0008-5472.CAN-05-3560

44. van der Pluijm G, Que I, Sijmons B, Buijs JT, Lowik CW, Wetterwald A et al (2005) Interference with the microenvironmental support impairs the de novo formation of bone metastases in vivo. Cancer Res 65:7682-7690. doi:10.1158/0008-5472.CAN-05-2468

45. Luker GD, Bardill JP, Prior JL, Pica CM, Piwnica-Worms D, Leib DA (2002) Noninvasive bioluminescence imaging of herpes simplex virus type 1 infection and therapy in living mice. J Virol 76:12149-12161. doi:10.1128/JVI.76.23.12149-12161.2002

46. Yu YA, Shabahang S, Timiryasova TM, Zhang Q, Beltz R, Gentschev I et al (2004) Visualization of tumors and metastases in live animals with bacteria and vaccinia virus encoding lightemitting proteins. Nat Biotechnol 22:313-320. doi:10.1038/ nbt937

47. Buijs JT, Henriquez NV, van Overveld PG, van der Horst G, Que I, Schwaninger R et al (2007) Bone morphogenetic protein 7 in the development and treatment of bone metastases from breast cancer. Cancer Res 67:8742-8751. doi:10.1158/0008-5472.CAN-06-2490

48. Fidler IJ (2003) The pathogenesis of cancer metastasis: the 'seed and soil' hypothesis revisited. Nat Rev Cancer 3:453-458. doi: $10.1038 / \mathrm{nrc} 1098$

49. Paget $S$ (1889) The distribution of secondary growths in cancer of the breast. Lancet 1:571-573. doi:10.1016/S0140-6736(00)49915-0

50. van der Pluijm G, Lowik C, Papapoulos S (2000) Tumour progression and angiogenesis in bone metastasis from breast cancer: new approaches to an old problem. Cancer Treat Rev 26:11-27. doi:10.1053/ctrv.1999.0143

51. Guise TA, Mohammad KS, Clines G, Stebbins EG, Wong DH, Higgins LS et al (2006) Basic mechanisms responsible for osteolytic and osteoblastic bone metastases. Clin Cancer Res 12:6213s-6216s. doi:10.1158/1078-0432.CCR-06-1007

52. Rodan GA (1998) Mechanisms of action of bisphosphonates. Annu Rev Pharmacol Toxicol 38:375-388. doi:10.1146/annurev. pharmtox.38.1.375

53. Fleisch H (1998) Bisphosphonates: mechanisms of action. Endocr Rev 19:80-100. doi:10.1210/er.19.1.80

54. Chung LW, Baseman A, Assikis V, Zhau HE (2005) Molecular insights into prostate cancer progression: the missing link of tumor microenvironment. J Urol 173:10-20

55. Claxton K, Ginnelly L, Sculpher M, Philips Z, Palmer S (2004) A pilot study on the use of decision theory and value of information analysis as part of the NHS Health Technology Assessment programme. Health Technol Assess 8:1-103 iii

56. Zhang H, Yano S, Miki T, Goto H, Kanematsu T, Muguruma $\mathrm{H}$ et al (2003) A novel bisphosphonate minodronate (YM529) specifically inhibits osteolytic bone metastasis produced by human small-cell lung cancer cells in NK-cell depleted SCID mice. Clin Exp Metastasis 20:153-159. doi:10.1023/A:1022621 622063

57. Yang M, Burton DW, Geller J, Hillegonds DJ, Hastings RH, Deftos LJ et al (2006) The bisphosphonate olpadronate inhibits skeletal prostate cancer progression in a green fluorescent protein 
nude mouse model. Clin Cancer Res 12:2602-2606. doi:10.1158/ 1078-0432.CCR-05-2050

58. Masarachia P, Weinreb M, Balena R, Rodan GA (1996) Comparison of the distribution of $3 \mathrm{H}$-alendronate and $3 \mathrm{H}$-etidronate in rat and mouse bones. Bone 19:281-290. doi:10.1016/8756-3282 (96)00182-2

59. Mari C, Catafau A, Carrio I (1999) Bone scintigraphy and metabolic disorders. Q J Nucl Med 43:259-267

60. Love C, Din AS, Tomas MB, Kalapparambath TP, Palestro CJ (2003) Radionuclide bone imaging: an illustrative review. Radiographics 23:341-358. doi:10.1148/rg.232025103

61. Kozloff KM, Weissleder R, Mahmood U (2007) Noninvasive optical detection of bone mineral. J Bone Mine Res 22:12081216. doi: $10.1359 / \mathrm{jbmr} .070504$

62. Seoane J (2006) Escaping from the TGFbeta anti-proliferative control. Carcinogenesis 27:2148-2156. doi:10.1093/carcin/ bg1068

63. Kang Y, Siegel PM, Shu W, Drobnjak M, Kakonen SM, CordonCardo $C$ et al (2003) A multigenic program mediating breast cancer metastasis to bone. Cancer Cell 3:537-549. doi:10.1016/ S1535-6108(03)00132-6

64. Kang Y, He W, Tulley S, Gupta GP, Serganova I, Chen CR et al (2005) Breast cancer bone metastasis mediated by the Smad tumor suppressor pathway. Proc Natl Acad Sci U S A 102:1390913914. doi:10.1073/pnas.0506517102

65. Yin JJ, Selander K, Chirgwin JM, Dallas M, Grubbs BG, Wieser $\mathrm{R}$ et al (1999) TGF-beta signaling blockade inhibits PTHrP secretion by breast cancer cells and bone metastases development. J Clin Invest 103:197-206. doi:10.1172/JCI3523

66. Thiery JP (2003) Epithelial-mesenchymal transitions in development and pathologies. Curr Opin Cell Biol 15:740-746. doi: 10.1016/j.ceb.2003.10.006
67. Zeisberg M, Hanai J, Sugimoto H, Mammoto T, Charytan D, Strutz F et al (2003) BMP-7 counteracts TGF-beta1-induced epithelial-to-mesenchymal transition and reverses chronic renal injury. Nat Med 9:964-968. doi:10.1038/nm888

68. Zeisberg M, Shah AA, Kalluri R (2005) Bone morphogenic protein-7 induces mesenchymal to epithelial transition in adult renal fibroblasts and facilitates regeneration of injured kidney. $\mathrm{J}$ Biol Chem 280:8094-8100. doi:10.1074/jbc.M413102200

69. Buijs JT, Rentsch CA, van der Horst G, van Overveld PG, Wetterwald A, Schwaninger R et al (2007) BMP7, a putative regulator of epithelial homeostasis in the human prostate, is a potent inhibitor of prostate cancer bone metastasis in vivo. Am J Pathol 171:1047-1057. doi:10.2353/ajpath.2007.070168

70. Chaudhari AJ, Darvas F, Bading JR, Moats RA, Conti PS, Smith DJ et al (2005) Hyperspectral and multispectral bioluminescence optical tomography for small animal imaging. Phys Med Biol 50:5421-5441. doi:10.1088/0031-9155/50/23/001

71. Ntziachristos V, Ripoll J, Wang LV, Weissleder R (2005) Looking and listening to light: the evolution of whole-body photonic imaging. Nat Biotechnol 23:313-320. doi:10.1038/nbt1074

72. Kok P, Dijkstra J, Botha CP, Post FH, Kaijzel EL, Que I et al (2007) Integrated visualization of multi-angle bioluminescence imaging and micro CT. Proc of SPIE 6509:1-10

73. Waarsing JH, Day JS, van der Linden JC, Ederveen AG, Spanjers C, De Clerck N et al (2004) Detecting and tracking local changes in the tibiae of individual rats: a novel method to analyse longitudinal in vivo micro-CT data. Bone 34:163-169. doi:10.1016/ j.bone.2003.08.012

74. Doubrovin M, Serganova I, Mayer-Kuckuk P, Ponomarev V, Blasberg RG (2004) Multimodality in vivo molecular-genetic imaging. Bioconjug Chem 15:1376-1388. doi:10.1021/bc0498572 